\title{
HAIRY CELL LEUKEMIA: LONG TERM RESPONSE TO CLADRIBINE.
}

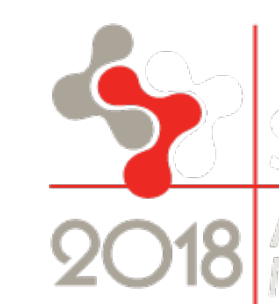

Anup J Devasia, Anu Korula, Ansu Abu Alex, Uday Kulkarni, Fouzia NA, Aby Abraham, Alok Srivastava, Biju George, Poonkuzhali Balasubramanyam, Vikram Mathews Department of Hematology, Christian Medical College, Vellore, India.

\section{INTRODUCTION}

Hairy cell leukemia $(\mathrm{HCL})$ is an indolent $B$ cell neoplasm characterised by constitutive cell proliferation signalling secondary to a point mutation in the BRAF (V600E).

Pancytopenia, organomegaly \& immunosuppression are hallmarks of $\mathrm{HCL}$

Response to purine analogue based therapy is excellent in the classical variant of $\mathrm{HCL}$.

Long term overall survival (OS) ranging from $80-90 \%$.

\section{PATIENTS AND METHODS}

Retrospective analysis of patients diagnosed with Hairy cell Leukemia at CMC, Vellore, India between January 2001-December 2017.

\section{Diagnosis based on :}

Peripheral blood

Bone marrow morphology

Special stains (TRAP),

Trephine biopsy with IHC

Flow cytometry

BRAF mutation
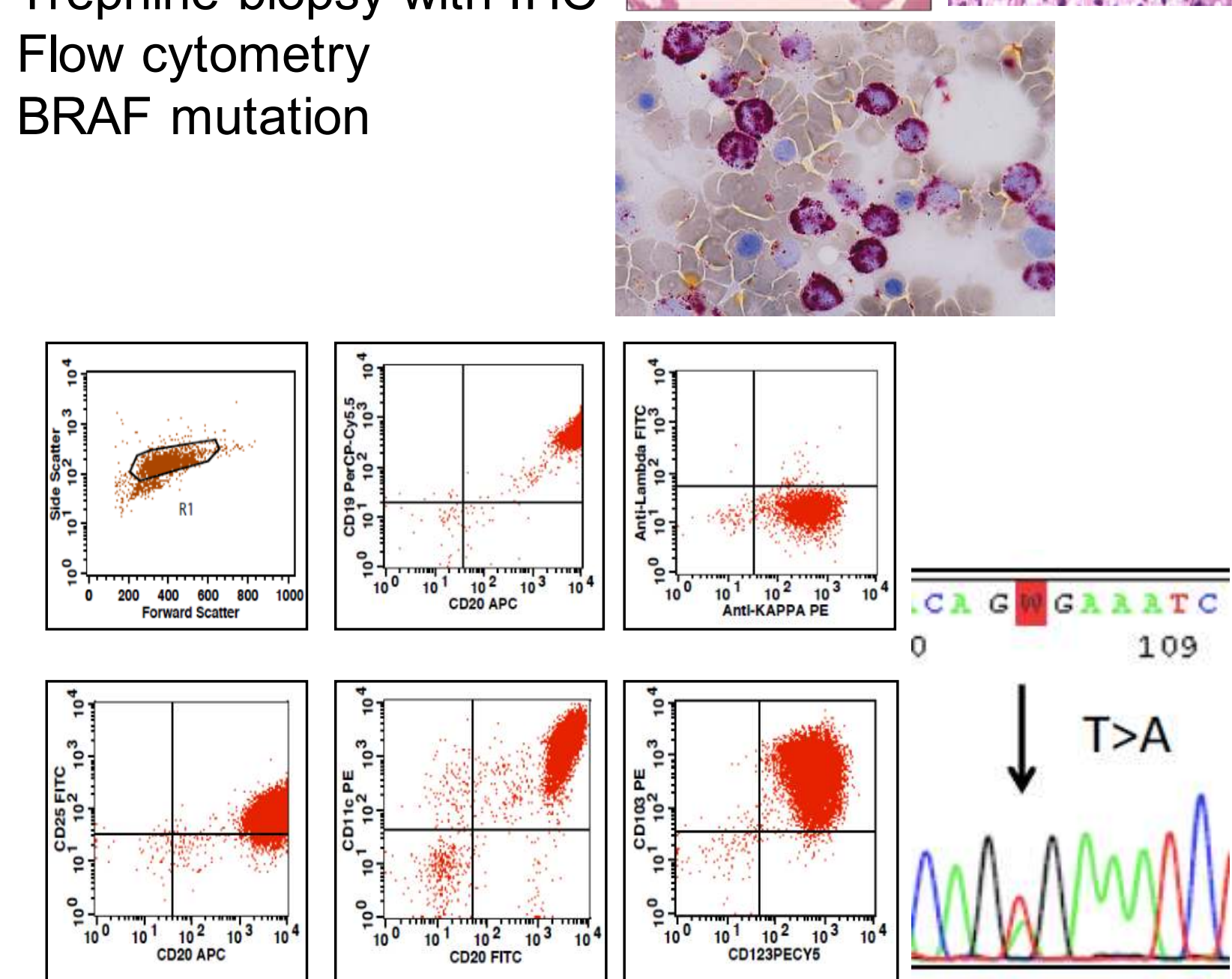

\section{RESULTS}

74 patients ( 70 males \& 4 females) with Classical HCL

5 patients ( 4 males $\& 1$ female) with variant $\mathrm{HCL}$

BASELINE CHARACTERISTICS OF PATIENTS WITH CLASSICAL HAIRY CELL LEUKEMIA

$\begin{array}{ll}\text { Median age (yrs.) 49(30-70) } & \text { 45) }\end{array}$

Symptomatic 68/74 (92\%)

Duration of symptoms (months) 3(1-24)

Common symptoms

Fatigue
55/74 (77\%)

$\begin{array}{ll}\text { Fever } & 31 / 74(42 \%)\end{array}$

Organomegaly

$\begin{array}{ll}\text { Hepatomegaly } & 27(36 \%) \\ \text { Splenomegaly } & 56(76 \%)\end{array}$

Cytopenia in 2 cell lines $\quad 45 / 74(61 \%)$

Cytopenia in 2 cell lines $\quad 45 / 74$ (61\%)

Hairycells in peripheral blood $\quad 29 / 74(39 \%)$

TRAP stain positive $\quad 51 / 60(89 \%)$

DBA44 positive 43/56 (77\%)

Annexin A positive 34/37 (92\%)

BRAF V600E (allelic PCR) mutation $\quad 32 / 32(100 \%)$

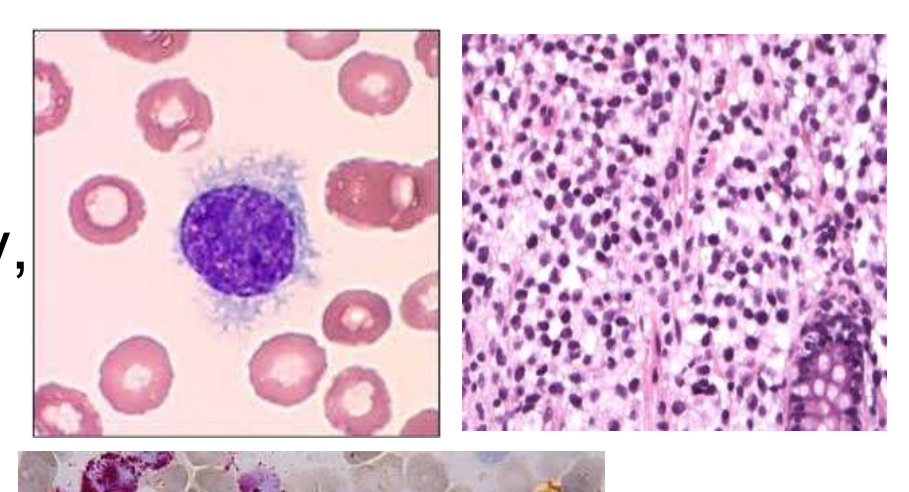

\section{TREATMENT OF RELAPSED PATIENTS}

5 patients relapsed at a median of 73 (36-104) months

Repeat Cladribine $\quad 4 / 5$

Cladribine + Rituximab

1 patient had a second relapse 2 years after salvage Cladribine, salvaged with Cladribine, died in cytopenia withfungal pneumonia

\begin{tabular}{|lc|}
\multicolumn{2}{l}{ VARIANT HAIRY CELL LEUKEMIA $(n=5)$} \\
Medianage & $67(39-83)$ \\
\hline Therapy & \\
Splenectomy & 3 \\
Cladribine + Fludarabine+ Rituximab & 1 \\
Followed up without treatment & 1 \\
\hline
\end{tabular}

without treatme

\section{1 in partial response}

1 patient relapsed after splenectomy, opted for palliation
TREATMENT OF PATIENIS WITH CLASSICAL HAIRY CELL LEUKEMIA

\begin{tabular}{|c|c|}
\hline $\begin{array}{l}\text { Treatment given } \\
\text { Cladribine } \\
\text { Splenectomy } \\
\text { No treatment, followed up } \\
\text { Opted for treatment elsewhere }\end{array}$ & $\begin{array}{c}53 / 74(72 \%) \\
2 \\
1 \\
19\end{array}$ \\
\hline \multicolumn{2}{|c|}{ CLADRIBINE THERAPY } \\
\hline Febrile Neutropenia & $44 / 53(83 \%)$ \\
\hline Median time to ANC $>1000$ & $22(10-157)$ \\
\hline Median time to platelets $>100000$ (days) & $17(6-29)$ \\
\hline Median duration of hospital stay & $22(8-40)$ \\
\hline \multicolumn{2}{|c|}{ RESPONSE TOCLADRIBINE THERAPY } \\
\hline Complete response in 48 patients & Partial response in 1 patient \\
\hline
\end{tabular}

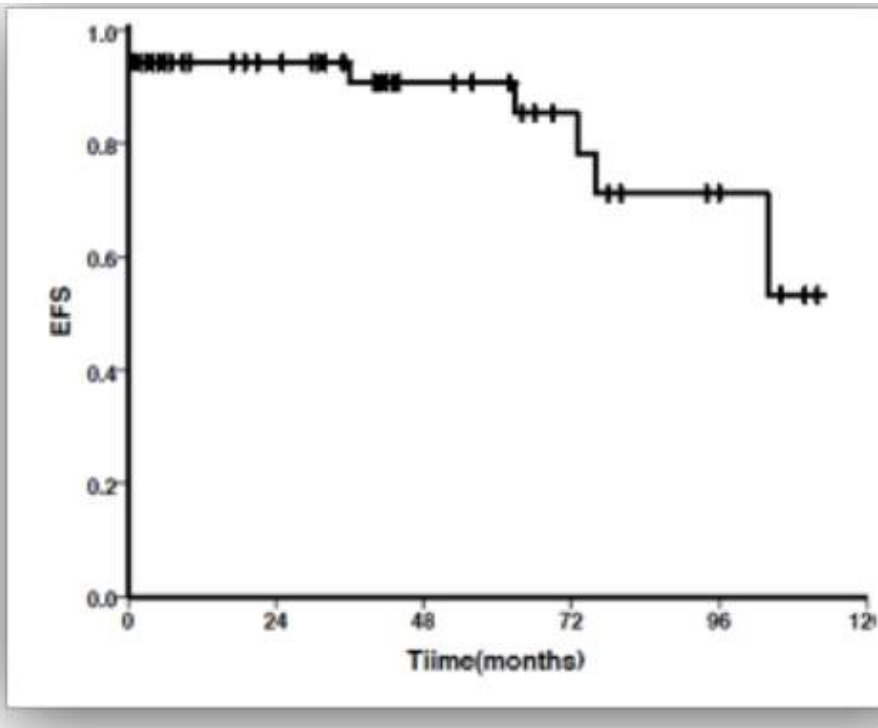

5 year EFS is $85.4 \pm 6.8 \%$

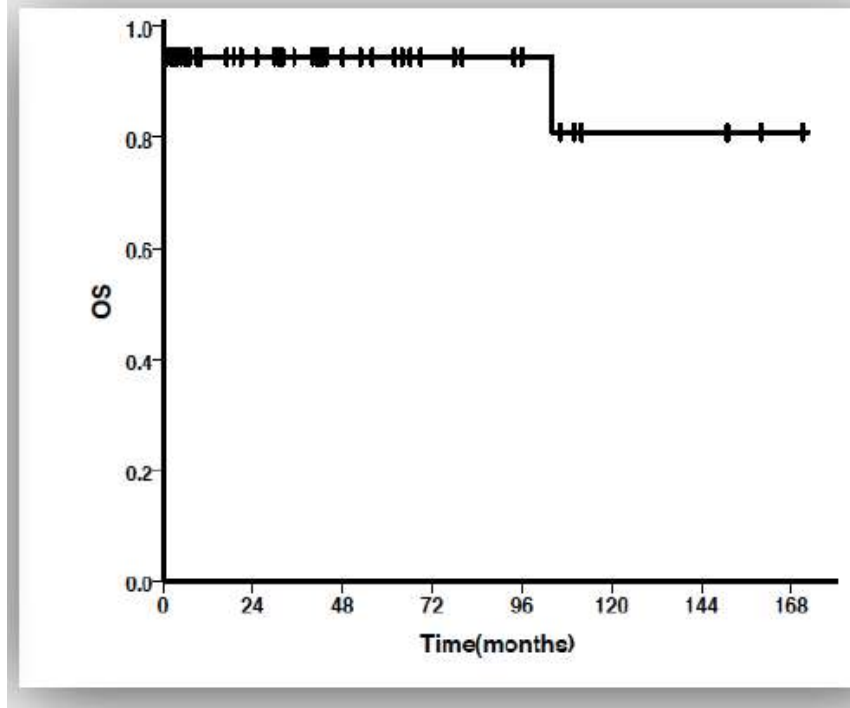

5 year OS is $94.3 \pm 3.2 \%$

\section{CONCLUSIONS}

Long term responses are seen with single agent Cladribine therapy in Classical Hairy cell leukemia.

Late relapses can still be managed with a repeat course of Cladribine.

Mortality secondary to multidrug resistant gram negative bacterial sepsis remains a concern. 